\title{
Risk factors for stillbirths: how much can a responsive health system prevent?
}

\author{
Sutapa Bandyopadhyay Neogi ${ }^{1 *}$, Jyoti Sharma ${ }^{1}$, Preeti Negandhi', Monika Chauhan ${ }^{1}$, Siddharth Reddy ${ }^{2}$ \\ and Ghanashyam Sethy ${ }^{2}$
}

\begin{abstract}
Background: The stillbirth rate is an indicator of quality of care during pregnancy and delivery. Good quality care is supported by a functional heath system. The objective of this study was to explore the risk factors for stillbirths, particularly those related to a health system.

Methods: This case-control study was conducted in two districts of Bihar, India. Information on cases (stillbirths) were obtained from facilities as reported by Health Management Information System; controls were consecutive live births from the same population as cases. Data were collected from 400 cases and 800 controls. The risk factors were compared using a hierarchical approach and expressed as odds ratio, attributable fractions and population attributable fractions.

Results: Of all the factors studied, 22 risk factors were independently associated with stillbirths. Health system-related factors were: administration of two or more doses of oxytocics to augment labour before reaching the facilities (OR 1.6; 95\% Cl 1.2-2.1), any complications during labour (OR 2.3;1.7-3.1), >30 min to reach a facility from home (OR 1.4;1.05-1. 8), >10 min to attend to the pregnant woman after reaching the facility (OR 2.8;1.7-4.5). In the final regression model, modifiable health system-related risk factors included: $>10$ min taken to attend to women after they reach the facilities (AOR 3.6; 95\% Cl 2.5-5.1), untreated hypertension during pregnancy (AOR 2.9; 95\% Cl 1.5-5.6) and presence of any complication during labour, warranting treatment (AOR 1.7; $95 \% \mathrm{Cl} 1.2-2.4$ ). Among mothers who reported complications during labour, time taken to reach the facility was significantly different between stillbirths and live births (2nd delay; $33.5 \mathrm{~min} \mathrm{v} / \mathrm{s} 25 \mathrm{~min} ; p<0.001$ ). Attributable fraction for any complication during labour was 0. $56(95 \% \mathrm{Cl} 0.42-0.67),>30$ min to reach the facility 0.48 (95\% Cl $0.31-0.60)$ and institution of management 10 min after reaching the facility 0.68 ( $95 \% \mathrm{Cl}$ 0.58-0.75). Reaching a facility within $30 \mathrm{~min}$, initiation of management within 10 min of reaching the facility and timely management of complications during labour could have prevented $17 \%, 37 \%$ and $20 \%$ of stillbirths respectively.
\end{abstract}

Conclusion: A pro-active health system with accessible, timely and quality obstetric services can prevent a considerable proportion of stillbirths in low and middle income countries.

Keywords: Stillbirths, Risk factors, Health systems, Low and middle income countries

\section{Background}

Stillbirth is an unfavourable outcome of pregnancy, which is still prevalent in many countries despite remarkable efforts to improve the care of pregnant women. Around 2.6 million third trimester stillbirths occur worldwide, out of which nearly $98 \%$ are reported from low and middle income countries (LMIC) [1]. The stillbirth rate (SBR) in

\footnotetext{
* Correspondence: sutapa.bneogi@iiphd.org

'Indian Institute of Public Health- Delhi, Public Health Foundation of India,

Gurugram, India

Full list of author information is available at the end of the article
}

India is $4 / 1000$ births [2]. These rates are likely to be underestimates, as data on stillbirths are difficult to capture [2, 3].

Several risk factors for stillbirths have so far been documented. Maternal factors, such as advanced maternal age, teenage pregnancies, maternal nutritional status, history of prior pregnancy losses, complicated pregnancies [4] and multiple pregnancies increase the risk of stillbirths. Poor socio-economic conditions have also been found to be associated with stillbirths [5-9]. In LMICs, quality of health care is an important risk factor for stillbirth, alongside other 
factors. Lack of access to antenatal care services, quality of care during childbirth and delayed caesarean sections are common risk factors [10].

In India, most data on stillbirths are from hospital-based studies. Population-based data are not collected routinely and those collected are subjected to gross under-reporting and selection bias [11]. Bihar is a high-priority Indian state with a significant burden of maternal and child mortality. The routine health data collected through the Health Management Information System (HMIS) collates information from health facilities across the country. In 2015, the HMIS reported an SBR of approximately $2 \%$ for institutional deliveries in the state [12]. However, the Sample Registration System (SRS), a geographically representative populationbased system of collecting data on vital statistics, reported the SBR in Bihar as 1 per 1000 births in 2015 [2].

Studies conducted in LMICs suggest that a sizeable proportion of stillbirths may have occurred during the intra-partum period, indicating that improved quality of care during childbirth and caesarean section can help prevent these stillbirths [13]. Moreover, there are anecdotal reports from certain parts of India on the administration of unwarranted use of oxytocics to augment labour, even in home deliveries [14, 15]. Studies have shown that oxytocin is used in most instances while some also administer misoprostol $[16,17]$. A small pilot study conducted by the same group of authors in a neighbouring district of the same state found that nearly $20 \%$ of the women received more than two doses of such medicines to augment labour before reaching the health facilities for delivery.

For this study, the objective was to investigate the association of potential risk factors including various socio-demographic and health system factors, with special reference to the practice of administering two or more doses of oxytocic medicines to augment labour, with stillbirths in two districts of Bihar.

\section{Methods}

This study was conducted in two UNICEF priority districts of Bihar -Gaya and Purnea- between July and August 2015 using a case-control study design. In these two districts, 23 blocks were chosen (16 from Gaya and 7 from Purnea) based on the number of stillbirths reported in HMIS from facilities. In order to minimize the extent of recall bias, the enrolment of participants was limited to the previous six calendar months.

\section{Sample size}

The sample size was calculated for a 1:2 case-control study, with the assumption that the prevalence of the principal exposure (administration of more than two doses of medicines to augment labour) is $20 \%$ among controls, power of $80 \%$, an estimated odds ratio (OR) depicting the strength of association between exposure and stillbirth of
1.5 , and the level of significance being 0.05 . The estimated sample size was 388 cases and 776 controls. This was rounded off to 400 cases and 800 controls.

\section{Study participants}

Definitions used to report cases of stillbirths vary across the country. For our study, we identified a case as "any baby born dead after the 24th week of pregnancy" [18]. "Born dead" included babies that did not breathe or cry or show other signs of life. Both singleton and multiple pregnancies were included. For selection of cases, the line lists of all facility-based stillbirths of the past 6 months were obtained from HMIS from the selected blocks. The interviewers then contacted the frontline workers of the respective villages/wards within these blocks to trace the mothers/ families of these stillborn babies. Mothers/families not willing to participate were excluded from the study. For each included case, two controls were identified. These controls were two live born babies from the same village/ ward as the case, born just before, at the same time or just after the case.

\section{Data collection}

A participant information sheet and consent form were developed for the study. A short screening tool was developed to differentiate stillbirths from early neonatal deaths. A validated World Health Organization (WHO) verbal autopsy semi-structured tool, adapted in our previous study, was used to collect data on risk factors $[18,19]$ [see Additional file 1]. Some context and region-specific factors were added, and pre-tested in the field before initiating data collection.

Trained interviewers visited the families of the stillbirths with the help of the information provided in the line lists, confirmed the cases of stillbirths based on the screening tool and obtained informed consent. For the confirmed stillbirths, controls were selected from the same area. The interviews took place at the homes of the participants and lasted for more than half an hour each. Data were collected on paper forms by giving a unique identification number, and later used for data entry and analyses. The data were collected by interviewing the mother and family members. Medical records were used wherever they were made available, especially for labour and delivery related information.

\section{Risk factors}

Risk factors mentioned in the literature and those listed in the WHO tool were included in the study. It is a reported common practice to administer oxytocics (usually oxytocin) during labour to the pregnant woman for augmentation [15-17]. The primary exposure considered was "administration of two or more doses of oxytocics during labour" before reaching the health facilities for 
delivery. Since the responses were obtained from the mothers, the term "medicines" was used as a proxy term for oxytocics. Mothers generally being unaware of the name of the medicines, we tried to confirm the intake of oxytocics by asking about the route of administration. Responses obtained as 'injections' were considered as proxy for oxytocin and those obtained as 'oral' were assumed to be misoprostol. Maternal factors including complications during pregnancy and delivery such as: history of bleeding during pregnancy or before delivery (ante-partum haemorrhage), a record of high blood pressure or a history given by the mother (pre-eclampsia), intake of drugs other than iron and calcium during pregnancy, exposure to active or passive smoking, and physical injury and violence as reported by mothers. Fetal factors included prematurity (assessed from gestational age in weeks calculated from last menstrual period, verified from records or elicited from history in the absence of records), low birth weight if records were available, and congenital malformations elicited from history. Information pertaining to approximate time taken to reach the facility for institutional deliveries, mode of transport and time taken to initiate management was reported by mothers/family members.

The modifiable health-system related risk factors included in the study were: less than the recommended number of antenatal-care visits (3) that can facilitate early identification of complications and timely management, administration of more than two doses of oxytocics to augment labour before reaching the health facilities, complications during labour that can be addressed with safe and skilled delivery, delay in reaching a facility, means of transport to reach a facility, and a delay in attending to the pregnant woman after reaching the facility.

\section{Data management}

A database was designed in Census and Survey Processing System (CS pro version 5.0, 2012). Data management included data entry, creation of data description tables, validation of database, cleaning, processing and analyses of data. Data were maintained in password-protected files and patient confidentiality was maintained at all times. Data access was restricted to the research team only.

\section{Statistical analyses}

Statistical Package for the Social Sciences (SPSS) version 19.0, 2010 was used for the quantitative analyses. A conceptual framework was developed to guide the analyses in which risk factors were categorized into four hierarchical levels [17]:

i) the sociodemographic factors such as age of the mother and father, their education, occupation were considered as the most distal determinants; ii) antenatal factors such as birth order, gestation period, history of previous stillbirths, early registration of pregnancy, number of antenatal visits, iron supplementation, ultrasonography, exposure of active or passive smoking, history of injury, accidents and physical violence, medical conditions like diabetes and intake of indigenous medicines during pregnancy were considered as the intermediate determinants; iii) factors during the last trimester of pregnancy such as vaginal bleeding, foul smelling discharge, burning micturition, oedema, severe or persistent abdominal pain, severe anemia requiring blood transfusion, high blood pressure were the proximate factors;

iv) labour and childbirth-related factors such as administration of 2 or more doses of oxytocics to augment labour, any complication during labour (such as convulsions, excessive bleeding, fever, high or low blood pressure, obstructed labour, excessive perspiration, blurring of vision), mode of transport to reach facilities, time taken to reach the facility and time taken to attend to the women after reaching the facilities.

Every factor with at least five respondents in each category was examined for association with the outcome of interest (live birth/stillbirth) using bivariate analyses. At every step in the analyses, $p<0.05$ was considered as the cut-off for statistical significance. For multivariable analyses, a hierarchical approach was used [20]. From Model 1 through to Model 4, we considered distal factors and moved to proximal ones in successive steps. The factors that were statistically significant or biologically plausible in one model were considered in the successive model, starting from sociodemographic factors (Model 1), antenatal factors (Model 2), factors related to the third trimester of pregnancy (Model 3), followed by delivery related factors in Model 4. Model 4 was the final multivariable regression analyses model.

Unadjusted and adjusted odds ratios (AOR) were calculated for the risk factors. Attributable fractions (AF) and population attributable fractions (PAF) were calculated for modifiable health system risk factors.

\section{Quality assurance measures}

Permission was sought from the State and district authorities at the outset. We obtained approval from Institutional Ethics Committee of Indian Institute of Public Health, Delhi, Public Health Foundation of India. Potentially eligible parents were given detailed information about the study in local language by the project team prior to data collection. Written consent was taken from every mother/family member who voluntarily agreed to participate in the study. 


\section{Results}

The interviewers screened a total of 421 cases of stillbirths prior to the interviews, from both districts based on the line lists available so as to meet the sample size. Cases were confirmed as stillbirths (based on signs of life immediately after birth) during the screening; it was observed that $21(5 \%)$ listed stillbirths were actually early neonatal deaths, falsely reported as stillbirths. These were excluded from the study. Thus, data were collected from 400 confirmed stillbirths and 800 controls.

\section{Socio-demographic variables}

The cases and controls, though comparable, were statistically significantly different with regards to maternal age, occupation of mothers, education and occupation of fathers (Table 1).

Table 1 Socio demographic profile of cases and controls

\begin{tabular}{|c|c|c|c|}
\hline Socio demographic variables & $\begin{array}{l}\text { Cases } n(\%) \\
N=400\end{array}$ & $\begin{array}{l}\text { Controls n (\%) } \\
N=800\end{array}$ & $p$-value \\
\hline Age of father (mean) in years & $27.32(4.2)$ & $27.5(3.2)$ & 0.26 \\
\hline Age of mother (mean) in years & $23.9(3.7)$ & $24.5(3.1)$ & $0.002^{*}$ \\
\hline Education of mothers & & & 0.78 \\
\hline Illiterate & $292(73.0 \%)$ & $563(70.4 \%)$ & \\
\hline Just literate & $66(16.5 \%)$ & $126(15.8 \%)$ & \\
\hline Primary school completed & $23(5.8 \%)$ & $59(7.4 \%)$ & \\
\hline $\begin{array}{l}\text { High and senior secondary } \\
\text { school completed }\end{array}$ & $18(4.5 \%)$ & $49(6.1 \%)$ & \\
\hline Graduation and above & $1(0.3)$ & $3(0.4)$ & \\
\hline Occupation of mothers & & & $0.016^{*}$ \\
\hline Agriculture & $31(7.8)$ & $105(13.2)$ & \\
\hline Home maker & $283(70.8)$ & $517(64.6)$ & \\
\hline Office job & 0 & $2(0.3)$ & \\
\hline Manual laborer & $84(21.0)$ & $175(21.9)$ & \\
\hline Others & $2(0.5)$ & $1(0.1)$ & \\
\hline Education of fathers & & & $<0.001^{*}$ \\
\hline Illiterate & $152(38.0)$ & $310(38.8)$ & \\
\hline Just literate & $120(30.0)$ & $207(25.8)$ & \\
\hline Primary school completed & $77(19.3)$ & $100(12.5)$ & \\
\hline $\begin{array}{l}\text { High and senior secondary } \\
\text { school completed }\end{array}$ & $44(11.1)$ & $162(20.3)$ & \\
\hline Graduation and above & $7(1.8)$ & $21.0(2.6)$ & \\
\hline Occupation of fathers & & & $0.023^{*}$ \\
\hline Agriculture & $127(31.8)$ & $248(31.0)$ & \\
\hline Office job & $8(2.0)$ & $26(3.3)$ & \\
\hline Industry & $24(6.0)$ & $85(10.7)$ & \\
\hline Manual laborer & $237(59.3)$ & $435(54.4)$ & \\
\hline Others & $4(1.1)$ & $6(0.7)$ & \\
\hline
\end{tabular}

*Values of $p<0.05$ considered as statistically significant difference or association, based on chi-square estimates for proportions and $t$-test for means
93\% (372/400) mothers had registered with health facilities during pregnancy. However, the proportions of first trimester registrations were $47 \%$ and $60 \%$ among cases and controls respectively. Also, a significantly higher proportion of mothers of controls had completed three or more antenatal visits (53.5\% v/s 35.3\% among cases). $1.3 \%$ of the stillbirths in the study were home deliveries, but had been referred to facilities subsequently. Among controls, $22.5 \%$ were born at home.

\section{Risk factors}

Of all the factors, 22 differed between cases and controls on bivariate analyses $(p<0.05)$ (Table 2$)$. History of augmentation of labour with two or more doses of oxytocics was significantly different between cases and controls (36.3\% v/s 26.1\%; $p<0.001)$.

A multivariable model was developed using a hierarchical approach with factors that had different distribution in cases and controls in bivariate analyses $(p<0.05)$. The final model (Model 4) explained 35\% (Nagelkerke $\mathrm{R}^{2}$ ) of the variance in the stillbirths and correctly classified $76.1 \%$ of cases.

Of all the risk factors examined, the final model included maternal age (more than 30 years), primigravidae, preterm labour ( $<37$ weeks), antenatal factors such as exposure to active or passive smoking, history of injury or accident, history of physical violence, bleeding per vagina, oedema, blurring of vision or severe headache and high blood pressure and intranatal factors such as complications during labour and time taken to attend to the pregnant woman after reaching the facility. Since blurring of vision, oedema and hypertension could be biologically related, we checked for collinearity, which was found to be poor, hence these variables were considered as independent variables for the analyses. Of these factors, the modifiable health system-related risk factors included longer than $10 \mathrm{~min}$ taken to attend to women after they reach the facilities (AOR 3.6; 95\% CI 2.5-5.1), untreated hypertension during pregnancy (AOR 2.9; 95\% CI 1.5-5.6) any complication during labour, warranting treatment (AOR 1.7; 95\% CI 1.2-2.4). Administration of two or more doses of oxytocics to augment labour was associated with stillbirths (Unadjusted OR 1.6; 95\% CI 1.2-2.1). However, the multivariable analyses failed to detect an association between the two factors (AOR 0.98, 95\% CI 0.7-1.4) (Table 3).

Among mothers of cases and controls who reported having some complications during labour, significant differences were observed in time taken to reach the facility (2nd delay ${ }^{1} ; 33.5 \mathrm{~min} \mathrm{v} / \mathrm{s} 25 \mathrm{~min}, p<0.001$ ) and time taken to initiate management (3rd delay ${ }^{1} ; 15.5 \mathrm{v} / \mathrm{s}$ 9 min, $p<0.001$ ). Our analyses indicated that women who had stillbirths were almost 4 times more likely to have been attended to after $10 \mathrm{~min}$ of reaching the facilities for delivery. 
Table 2 Risk factors for stillbirths among cases and controls - bivariate analyses

\begin{tabular}{|c|c|c|c|}
\hline Risk factors & $\begin{array}{l}\text { Cases } n(\%) \\
n=400\end{array}$ & $\begin{array}{l}\text { Controls n (\%) } \\
n=800\end{array}$ & $p$-value \\
\hline \multicolumn{4}{|l|}{ Sociodemographic factors } \\
\hline Age of the mother $>30$ years & $23(5.8)$ & $15(1.9)$ & $<0.001^{*}$ \\
\hline Occupation of mother (working outside home) & $117(29.3)$ & $283(35.4)$ & $0.03^{*}$ \\
\hline Education of father (illiterate) & $152(38.0)$ & $310(38.8)$ & 0.8 \\
\hline Occupation of father (non-manual labourer) & $163(40.8)$ & $365(45.6)$ & 0.11 \\
\hline Sex of the child (male) $)^{a}$ & 218/393 (55.4) & $485 / 800(61.1)$ & \\
\hline \multicolumn{4}{|l|}{ Antenatal factors } \\
\hline \multicolumn{4}{|l|}{ Birth order } \\
\hline Primigravidae & $174(43.5)$ & $275(34.4)$ & $<0.001^{*}$ \\
\hline Multigravidae & $226(56.5)$ & $525(65.6)$ & \\
\hline \multicolumn{4}{|l|}{ Gestation period $(n=1178)$} \\
\hline$<28$ weeks & 0 & $3(0.4)$ & $<0.001^{*}$ \\
\hline$<37$ weeks & $298(75.3)$ & $286(36.7)$ & \\
\hline $\begin{array}{l}\text { Mean interval between present and the last pregnancies } \\
\text { among multigravida (months) }\end{array}$ & $20.1(10.3)$ & $20.2(9.4)$ & 0.9 \\
\hline Any previous stillbirths among multigravida mothers & $33(14.6)$ & $59(11.3)$ & 0.2 \\
\hline Registered with health facility during pregnancy & $372(93.0)$ & $754(94.3)$ & 0.39 \\
\hline Proportion of women registered in 1st trimester & $187(46.8)$ & $479(59.9)$ & $<0.001^{*}$ \\
\hline Received 3 or more ANC checkups & $141(35.3)$ & $428(53.5)$ & $<0.001^{*}$ \\
\hline Intake of iron tablets during pregnancy & $263(65.8)$ & $567(70.9)$ & 0.07 \\
\hline Multiple pregnancy (current pregnancy) & $4(1.0)$ & $6(0.8)$ & 0.65 \\
\hline Tetanus toxoid during pregnancy & $385(96.3)$ & $772(96.5)$ & 0.83 \\
\hline Ultrasound during pregnancy & $104(26)$ & $205(25.6)$ & 0.9 \\
\hline Exposure to active or passive smoking & $156(39)$ & $170(21.3)$ & $<0.001^{*}$ \\
\hline History of chewing tobacco during pregnancy & $89(22.3)$ & $59(7.4)$ & $<0.001^{*}$ \\
\hline History of injury or accident during pregnancy & $41(10.3)$ & $11(1.4)$ & $<0.001^{*}$ \\
\hline History of any physical violence during pregnancy & $50(12.5)$ & $56(7.0)$ & $0.002^{*}$ \\
\hline Gestational diabetes & $12(3.0)$ & $30(3.8)$ & 0.5 \\
\hline Intake of indigenous medicines during pregnancy & $25(6.3)$ & $33(4.1)$ & 0.44 \\
\hline \multicolumn{4}{|l|}{ Factors during last trimester of pregnancy } \\
\hline Bleeding per vagina during pregnancy & $146(36.5)$ & $106(13.3)$ & $<0.001^{*}$ \\
\hline Excessive or foul smelling vaginal discharge during pregnancy & $75(18.8)$ & $62(7.8)$ & $<0.001^{*}$ \\
\hline Burning micturition & $199(49.8)$ & $312(39.0)$ & $<0.001^{*}$ \\
\hline Oedema (hand or face or legs) & $225(56.3)$ & $317(39.6)$ & $<0.001^{*}$ \\
\hline Severe or persistent abdominal pain during pregnancy (not labour pain) & $131(32.8)$ & $211(26.4)$ & $0.02^{*}$ \\
\hline Blurring of vision or severe headache during pregnancy & $132(33.0)$ & $123(15.4)$ & $<0.001^{*}$ \\
\hline Severe anemia requiring blood transfusion & $19(4.8)$ & $26(3.3)$ & 0.2 \\
\hline High blood pressure during pregnancy & $46(11.5)$ & $21(2.6)$ & $<0.001^{*}$ \\
\hline \multicolumn{4}{|l|}{ Factors related to labour and childbirth } \\
\hline Any complication during labour & $140(35.0)$ & $152(19.0)$ & $<0.001^{*}$ \\
\hline Administration of 2 or more doses of medicines to augment labour & $145(36.3)$ & $208(26.1)$ & $<0.001^{*}$ \\
\hline Duration of labour (12 h or more) & $37(9.3)$ & $71(8.9)$ & 0.53 \\
\hline
\end{tabular}


Table 2 Risk factors for stillbirths among cases and controls - bivariate analyses (Continued)

\begin{tabular}{|c|c|c|c|}
\hline Risk factors & $\begin{array}{l}\text { Cases n (\%) } \\
n=400\end{array}$ & $\begin{array}{l}\text { Controls n (\%) } \\
n=800\end{array}$ & $p$-value $e^{*}$ \\
\hline Mode of transport to reach facilities & $n=395$ & $n=616$ & $<0.001^{*}$ \\
\hline Ambulance & $93(23.5)$ & $148(23.9)$ & \\
\hline Private vehicle & $200(50.6)$ & $374(60.4)$ & \\
\hline Any public transport & $102(25.8)$ & $94(15.0)$ & \\
\hline Time taken to reach facility & $n=393$ & $n=616$ & \\
\hline Up to $30 \mathrm{~min}$ & $253(64.4)$ & $439(71.3)$ & $0.02^{*}$ \\
\hline$>30 \mathrm{~min}$ & $140(35.6)$ & $177(28.7)$ & \\
\hline Time to attend after reaching the facility & $n=392$ & $n=615$ & \\
\hline Up to $10 \mathrm{~min}$. & $171(43.5)$ & $390(63.4)$ & $<0.001^{*}$ \\
\hline$>10$ min. & $222(56.5)$ & $225(36.6)$ & \\
\hline \multicolumn{4}{|l|}{ Mode of delivery ${ }^{\mathrm{b}}$} \\
\hline Vaginal (spontaneously or with little maneuver) & $375(93.7)$ & $783(98.1)$ & \\
\hline Instrumental delivery & $24(6.0)$ & $10(1.3)$ & \\
\hline Caesarean section & $1(0.3)$ & $5(0.6)$ & \\
\hline \multicolumn{4}{|l|}{ Presence of any visible structural birth defect ${ }^{b}$} \\
\hline Yes & $3(0.8 \%)$ & $3(0.4 \%)$ & \\
\hline No & $350(87.5 \%)$ & 782 (97.8\%) & \\
\hline Do not know & 47 (11.8\%) & 15 (1.9\%) & \\
\hline
\end{tabular}

*Values of $p<0.05$ considered as statistically significant difference or association, based on chi-square estimates for proportions

${ }^{a}$ Sex of stillborn children was not reliable hence was not considered for analyses

${ }^{\mathrm{b}}$ Because the cell size was less than 5 , these were not included in the analyses

Apart from medical factors, some social factors predisposed the pregnant women to stillbirths. Mothers of stillborn children were 2.5 times more likely to have been a victim of physical violence during pregnancy, as compared to mothers of controls. Exposure to active or passive smoking almost doubled the chances of stillbirth.

AF for any complication during labour was $0.56(95 \%$ CI $0.42-0.67$ ), more than $30 \mathrm{~min}$ to reach the facility was 0.48 (95\% CI $0.31-0.60)$ and initiation of management 10 min after reaching the facility was 0.68 (95\% CI 0.58-0.75). Reaching a facility within $30 \mathrm{~min}$, initiation of management within $10 \mathrm{~min}$ of reaching the facility and timely management of complications during labour could have prevented $17 \%, 37 \%$ and $20 \%$ of stillbirths respectively.

\section{Discussion}

In the present population-based case-control study, untreated hypertension during pregnancy, longer than $10 \mathrm{~min}$ taken to attend to pregnant women when they reach the facilities for delivery and presence of any complication during labour that warrants treatment emerged as significant modifiable health system risk factors for stillbirths. The other risk factors included increased maternal age, preterm births, primigravidae, exposure to active or passive smoking, and history of injury or physical violence during pregnancy.
Stillbirths is a sensitive marker of the strength of the health system [21]. In Indian settings, stillbirths have customarily been under-reported, given the lack of consistency in the definitions and lack of demand for data surrounding stillbirths [22]. Additionally, early neonatal deaths are falsely reported as stillbirths; in a study conducted elsewhere in India it was found to be 15\% [18]. Irrespective of settings, the largest proportions of stillbirths are antepartum deaths [23]. In India, the current reporting system for stillbirths does not include their categorization as fresh or macerated. As a result, it is difficult to differentiate the antepartum stillbirths from intrapartum stillbirths. Moreover, due to the retrospective nature of our study design, it was difficult to elicit whether the stillbirths were antepartum or intrapartum, hence they were considered as one group in this study.

Identification of high-risk pregnancies during antenatal period can facilitate timely initiation of therapy and referral to the appropriate facility to prevent or minimise antepartum deaths [24]. In our study, the coverage of antenatal care was less than $60 \%$ even among live births, thereby plummeting the chances of early identification and management of high-risk pregnancies. It is suggested that four antenatal visits may not positively impact the outcome of pregnancy until the coverage is at least $60 \%$ [21]. Women with high blood pressure in pregnancy were almost three times more likely to have stillbirths. In our study, $52 \%$ of 
Table 3 Multivariable analysis of risk factors for stillbirths using hierarchical approach

\begin{tabular}{|c|c|c|c|c|}
\hline Risk factors & Model 1 & Model 2 & Model 3 & Model 4 \\
\hline \multicolumn{5}{|l|}{ Sociodemographic factors } \\
\hline Age of the mother $>30$ years & $3.2(1.6-6.2)$ & $3.8(1.2-8.0)$ & $3.5(1.7-7.5)$ & $4.3(1.7-10.7)$ \\
\hline Occupation of mother (working outside home) & & - & - & - \\
\hline \multicolumn{5}{|l|}{ Antenatal factors } \\
\hline Birth order (primigravidae) & & $1.7(1.3-2.3)$ & $1.6(1.2-2.2)$ & $1.8(1.3-2.6)$ \\
\hline Preterm labour (<37 weeks) & & $4.8(3.6-6.5)$ & $4.0(2.9-5.5)$ & $4.5(3.2-6.5)$ \\
\hline Registration of pregnancy in first trimester & & $0.5(0.4-0.7)$ & $0.6(0.4-0.8)$ & - \\
\hline Received 3 or more ANC checkups & & $0.8(0.6-1.0)$ & $1.0(0.7-1.4)$ & - \\
\hline Exposure to active or passive smoking & & $1.9(1.4-2.6)$ & $2.3(1.7-3.3)$ & $2.1(1.4-3.0)$ \\
\hline History of chewing tobacco during pregnancy & & $1.6(1.0-2.5)$ & $1.5(0.9-2.3)$ & - \\
\hline History of injury or accident during pregnancy & & $4.3(2.0-9.3)$ & $4.3(2.0-9.5)$ & $10.7(3.4-33.7)$ \\
\hline History of any physical violence during pregnancy & & $2.0(1.2-3.3)$ & $2.3(1.4-3.9)$ & $2.5(1.4-4.6)$ \\
\hline \multicolumn{5}{|l|}{ Factors during last trimester of pregnancy } \\
\hline Bleeding per vagina during pregnancy & & & $2.2(1.5-3.2)$ & $2.6(1.7-3.8)$ \\
\hline Excessive or foul smelling vaginal discharge during pregnancy & & & - & - \\
\hline Burning micturition & & & $1.4(1.0-1.9)$ & - \\
\hline Oedema (hand or face or legs) & & & $1.4(1.1-1.9)$ & $1.8(1.3-2.6)$ \\
\hline Severe or persistent abdominal pain during pregnancy (not labour pain) & & & - & - \\
\hline Blurring of vision or severe headache during pregnancy & & & $1.7(1.2-2.5)$ & $1.9(1.3-2.8)$ \\
\hline High blood pressure during pregnancy & & & $3.1(1.6-5.8)$ & $2.9(1.5-5.6)$ \\
\hline \multicolumn{5}{|l|}{ Factors related to labour and childbirth } \\
\hline Any complication during labour ${ }^{a}$ & & & & $1.7(1.2-2.4)$ \\
\hline Administration of 2 or more doses of medicines to augment labour & & & & - \\
\hline Time take to reach facility (>30 mins) & & & & - \\
\hline More than 10 mins to attend after reaching the facility & & & & $3.6(2.5-5.1)$ \\
\hline
\end{tabular}

${ }^{a}$ Complication during labour include convulsions, excessive bleeding, fever, high or low blood pressure, obstructed labour, excessive perspiration, blurring vision and kidney failure

women with high blood pressure among cases reported having consumed antihypertensive medications while it was $62 \%$ among controls, although compliance to advice and medication would be a concern in both groups. Similar findings have been reported from other studies [25, 26] suggesting that early diagnosis and adequate medical intervention for hypertensive disorders can help reduce the risk of stillbirths.

Exposure to active or passive smoking led to an almost 2-fold risk of having a stillborn baby in our study, similar to existing evidence that maternal smoking was associated with a $47 \%$ increase in the odds of stillbirth [27]. Mothers of stillbirths were more likely $(p=0.002)$ to have been the victims of physical violence during pregnancy, which was similar to other studies $[28,29]$. Since this information is quite sensitive in nature, there is a likelihood of underreporting [30]. This may have resulted in a non-differential misclassification of the exposure, meaning that the actual strength of association might be more than what is reported in this study.
The optimal caesarean section (CS) rate to reduce the proportion of intra-partum stillbirths lie between 5 and $10 \%$ [31]. Evidence from LMICs shows that with every percentage rise in CS rate from 0 to $8 \%$, intra-partum stillbirth drops by 1.6 per 1000 births [31]. The rate of CS in our study was $<1 \%$, far below the optimal rates. Studies have also demonstrated that good quality obstetric care, and not mere provision of CS services, is critical [32]. In a recent analysis, the maximum benefit was noted from appropriate care during labour and childbirth, including complications $(70 \%$ of all stillbirths averted), followed by enhanced antenatal care focussing on detection of complications (21\%) [33]. The proportions of instrumental deliveries among the cases and controls in our study were $6 \%$ and $1.3 \%$ respectively. There may be instances in which instruments might have been applied to expedite the delivery in a confirmed case of stillbirth. Hence, it is difficult to interpret the association between instrumental deliveries and stillbirths. 
In our study, mothers who delivered prematurely were 4.5 times more likely to have a stillborn child, as compared to full-term deliveries. Preterm births and low birth weight babies increase the risk of stillbirths manifold [34]. A study highlighted that spontaneous preterm birth or preterm ruptured membranes were the key factors in $41 \%$ of stillbirths less than 28 gestational weeks [35]. This is in sharp contrast to our study where more than $75 \%$ stillbirths occurred between 28 and 37 weeks of gestation, although we took 24 weeks as the cut-off to identify stillbirths. However, it is not known how many stillbirths could have been averted through public health interventions like administration of antibiotics for preterm, premature rupture of membranes and antenatal corticosteroids for preterm labour [36].

In our study, administration of two or more doses of oxytocics to augment labour was associated with stillbirths in the unadjusted analyses. More than 35\% mothers of stillborn children and 25\% mothers of live born babies reported the use of such medications before reaching the facilities. Previous studies from India have shown that unwarranted use of oxytocics increases the risk of stillbirth, similar to our finding when considered independently [14, 16, 17, 37]. Oxytocics are usually administered only for a valid indication in facilities with provision for C-Sections [38]. Use of such oxytocics only to hasten the process of delivery without a valid indication and medical supervision may be detrimental. Nevertheless, rational use of oxytocics in health facilities along with regular intrapartum monitoring can positively favour obstetric outcomes.

Substandard obstetric care contributes to $20-30 \%$ of all stillbirths [35]. Reaching a facility within $30 \mathrm{~min}$, initiation of management within $10 \mathrm{~min}$ of reaching the facility and timely management of complications during labour could have prevented $17 \%, 37 \%$ and $20 \%$ of stillbirths respectively, according to our analyses. It is comparable to the estimated reduction in stillbirths by $25 \%$ with $60 \%$ coverage of basic interventions for skilled obstetric care [36]. This is however true only for prevention of intra-partum stillbirths. In our study, nearly $21 \%$ of mothers of cases and $48 \%$ mothers among controls admitted that they felt the last fetal movement during labour implying that more cases could have been antepartum stillbirths.

The study had its own set of limitations. Birth weight is an important parameter, since management of fetal growth restriction can avert $20 \%$ of antepartum and intrapartum stillbirths [36]. However, weighing of stillborn babies is not yet practiced in India [18]. Stillbirth reporting has improved through routine HMIS, however recording of all birth outcomes using comparable definitions, antepartum versus intra-partum stillbirths and birth weight are weak links within the system $[29,34]$. This was observed in our study as well. Increased and improved data availability can provide a solution for targeted interventions where those would be most effective [1]. Also, since the cases in our study were chosen from lists available at healthcare facilities, those women who had a stillbirth at home and who never visited the facilities for any post-partum complications were missed out completely, since they would not be registered in the HMIS. This was a major limitation in a situation where one-third to one-fourth of the deliveries take place at home. In the absence of reliable data, we were not certain if home-delivered stillbirths are different from facility-based stillbirths. Home-based stillbirths may be less likely to exhibit complications compared to facility stillbirths. There is a likelihood of bias resulting due to differential misclassification, which can change the direction of the observed association. The sample size was calculated considering administration of more than two doses of oxytocics to augment labour as the principal exposure. For the remaining factors, exploratory analysis was conducted and hence may not have been adequately powered to establish an association.

Besides these, our inability to differentiate between antepartum and intrapartum stillbirths remains a major challenge. Since we are focussing on health system related factors, it would have been useful to analyse the two groups separately. Paucity of this information might have led to undermining of the actual effect. From the reported information on the instrumental deliveries, it is difficult to ascertain if instruments were used more often to expel stillborn babies or these were used to deliver live babies who were later declared as stillborns when the babies were found dead. Approximate time to reach the facilities and time to initiate management after reaching the facilities were selfreported by mothers/family members. This could have resulted in recall bias; we tried to minimize this bias by keeping the interval between the event and the interview to less than 6 months. However, this might have affected both the groups leading to non-differential misclassification and hence the actual strength of association could be more than what is inferred from this study.

Since autopsies or other tests were not performed on stillborn babies, it is difficult to establish any causation. This poses a hindrance to understanding the cause of death, and increases the proportion of unexplained deaths [35]. Use of a validated verbal autopsy tool to collect data could address this lacuna to some extent. The tool has reasonable validity in identifying and discriminating between causes of stillbirth [19, 39, 40]. Any history of medical complication during pregnancy in our study was corroborated from available records. In our setting, availability of medical records was a challenge, thus resulting in probable reporting bias. However, our study focussed on risk factors and not causes of stillbirths. Besides, this study though representative of the state, focussed mainly on rural populations. 
Despite these limitations, the study highlights the importance of basic and advanced antenatal and intra-natal care for averting stillbirths. Conducted on a large sample and in household settings, the study captured existing factors related to obstetric care. This work is one of the few exploratory studies which have used routine health information system data to identify stillbirths from the community in this setting. Yet another strength of this study was the ability to relate the health-system related risk factors with stillbirths.

\section{Conclusions}

To conclude, a strong health system with a good coverage of basic antenatal care and timely institution of emergency obstetric services can avert a significant proportion of stillbirths in similar settings. A good quality antenatal care package can improve compliance, and detect complications early during pregnancy for timely action. Certain unwarranted complications that may occur during the last trimester of pregnancy can also be adequately addressed with appropriate measures taken as soon as women reach the health facility. Stillbirths are adverse pregnancy outcomes, most of which can be averted by a pro-active and strong health system through appropriate obstetric practices. Judicious use of oxytocics and other medications during labour can improve pregnancy outcomes. Additionally, mechanisms to improve routine surveillance of stillbirths to detect contributory factors and the reporting of stillbirths including information on birth weight and fresh vs. macerated stillbirth would contribute to strengthening the health information system.

\section{Endnotes}

${ }^{1}$ Time taken for a pregnant woman to reach a facility for delivery is termed as 2nd delay and time taken to initiate management after she reaches a facility is termed as 3rd delay. These are part of the 3 delay model which identifies three groups of factors affecting women accessing safe maternal healthcare.

\section{Additional file}

Additional file 1: Verbal Autopsy tool. Description: Used for collecting data related to stillbirths from mothers. (PDF $384 \mathrm{~kb}$ )

\section{Abbreviations}

AF: Attributable Fraction; AOR: Adjusted Odds Ratio; CS: Caesarean Section; HMIS: Health Management Information System; ICD-10: The International Classification of Diseases, 10th revision; LMIC: Low and Middle Income countries; OR: Odds Ratio; PAF: Population Attributable Fraction; PHFI: Public Health Foundation of India; RR: Relative Risk; SBR: Still Birth Rate; SRS: Sample Registration System
}

\section{Acknowledgements}

The research team acknowledges the contribution of Sarvodaya Vikash Samiti who had collected the data for the study. The team is grateful to Dr. Swati Katoch, Dr. Poonam Banga, Dr. Rashid, Mr. Shirish and Dr. Suman Bhardwaj for supervising the team in the field during data collection. We are also thankful to Mr. Manoj Soni, Data Management and Support Unit, IIPH Delhi for helping the team with database development and data management. The study team is grateful to the ASHAs, ANMs and families who helped us immensely to support towards collection of data for the study.

\section{Funding}

UNICEF, Bihar, supported the activity. The authors from UNICEF had facilitated the activity in the field and had no role in conceptualization of the study, data collection, analysis and interpretation of data. The views expressed in the manuscript are that of authors' and not of the organizations they represent.

\section{Availability of data and materials}

The dataset supporting the conclusions of this article are available with the corresponding author.

\section{Authors' contributions}

SN conceptualized the study, designed it, and drafted the manuscript. She provided overall leadership to the work. JS contributed to data analysis and finalized the manuscript. PN reviewed literature, coordinated the project and finalized the manuscript. MC reviewed the literature and finalized the manuscript. SR and GS facilitated the process of data collection in the field, and gave critical inputs during finalization of the manuscript. All the authors have read and approved the final version of the manuscript.

\section{Ethics approval and consent to participate}

Permission was sought from the State and district authorities. Approval was obtained from Institutional Ethics Committee of Indian Institute of Public Health, Delhi, Public Health Foundation of India. Written consent was taken from every mother/family member who voluntarily agreed to participate in the study.

\section{Consent for publication}

The manuscript does not contain any individual person's data or images.

\section{Competing interests}

SR and GS are employees of UNICEF, who funded the study, while the other authors have no competing interests.

\section{Publisher's Note}

Springer Nature remains neutral with regard to jurisdictional claims in published maps and institutional affiliations.

\section{Author details}

'Indian Institute of Public Health- Delhi, Public Health Foundation of India, Gurugram, India. ${ }^{2}$ UNICEF, Bihar, India.

Received: 21 July 2016 Accepted: 7 January 2018

Published online: 18 January 2018

\section{References}

1. Lawn JE, Blencowe H, Waiswa P, Amouzou A, Mathers C, Hogan D, Flenady V, Froen JF, Qureshi ZU, Calderwood C, et al. Stillbirths: rates, risk factors, and acceleration towards 2030. Lancet. 2016;387(10018):587-603.

2. SRS statistical report In. New Delhi Registrar General of India.; 2013

3. Stanton C, Lawn JE, Rahman H, Wilczynska-Ketende K, Hill K. Stillbirth rates: delivering estimates in 190 countries. Lancet. 2006;367(9521):1487-94.

4. Quality Assurance Project, Center for Human Services: Sustaining Quality of Healthcare: Institutionalization of Quality Assurance. http://pdf.usaid.gov/ pdf_docs/PNACS123.pdf. In.

5. McClure EM, Pasha O, Goudar SS, Chomba E, Garces A, Tshefu A, Althabe F, Esamai F, Patel A, Wright LL, et al. Epidemiology of stillbirth in low-middle income countries: a global network study. Acta Obstet Gynecol Scand. 2011;90(12):1379-85.

6. Harrison MS, Ali S, Pasha O, Saleem S, Althabe F, Berrueta M, Mazzoni A, Chomba E, Carlo WA, Garces A, et al. A prospective population-based study of maternal, fetal, and neonatal outcomes in the setting of prolonged labor, obstructed labor and failure to progress in low- and middle-income countries. Reproductive health. 2015;12(Suppl 2):S9.

7. Gardosi J, Madurasinghe V, Williams M, Malik A, Francis A. Maternal and feta risk factors for stillbirth: population based study. BMJ. 2013;346:f108. 
8. Bhattacharyya R, Pal A. Stillbirths in a referral medical college hospital, West Bengal, India: a ten-year review. J Obstet Gynaecol Res. 2012;38(1):266-71.

9. Aminu M, Unkels R, Mdegela M, Utz B, Adaji S, van den Broek N. Causes of and factors associated with stillbirth in low- and middle-income countries: a systematic literature review. BJOG : an international journal of obstetrics and gynaecology. 2014;121(Suppl 4):141-53.

10. Lawn JE, Kinney M, Lee AC, Chopra M, Donnay F, Paul VK, Bhutta ZA, Bateman M, Darmstadt GL. Reducing intrapartum-related deaths and disability: can the health system deliver? Int J Gynaecol Obstet. 2009;107(Suppl 1):S123-40. S140-122

11. Kulkarni R, Chauhan S, Shah B, Menon G, Puri C. Investigating causes of perinatal mortality by verbal autopsy in Maharashtra, India. Indian J Community Med. 2007;32(4):259.

12. Performance of Key HMIS Indicators for Bihar ( Across Districts) Financial Year: 2015-16. In. New Delhi Health Management Infromation System, Ministry of Health and Familly Welfare, Govt. of India 2015.

13. Lawn JE, Blencowe H, Pattinson R, Cousens S, Kumar R, Ibiebele I, Gardosi J, Day LT, Stanton C. Stillbirths: where? When? Why? How to make the data count? Lancet. 2011;377(9775):1448-63.

14. Iyengar K, Jain M, Thomas S, Dashora K, Liu W, Saini P, Dattatreya R, Parker I, lyengar $\mathrm{S}$. Adherence to evidence based care practices for childbirth before and after a quality improvement intervention in health facilities of Rajasthan, India. BMC Pregnancy and Childbirth. 2014;14(1):1-12.

15. Deepak NN, Mirzabagi E, Koski A, Tripathi V. Knowledge, attitudes, and practices related to uterotonic drugs during childbirth in Karnataka, India: a qualitative research study. PLoS One. 2013;8(4):e62801.

16. Jeffery P, Das A, Dasgupta J, Jeffery R. Unmonitored intrapartum oxytocin use in home deliveries: evidence from Uttar Pradesh, India. Reprod Health Matters. 2007;15(30):172-8.

17. Sharan M, Strobino D, Ahmed S. Intrapartum oxytocin use for labor acceleration in rural India. Int J Gynaecol Obstet. 2005;90(3):251-7.

18. Neogi SB, Negandhi P, Chopra S, Das AM, Zodpey S, Gupta RK, Gupta R. Risk factors for stillbirth: findings from a population-based case-control study, Haryana, India. Paediatr Perinat Epidemiol. 2016;30(1):56-66

19. Aggarwal AK, Jain V, Kumar R. Validity of verbal autopsy for ascertaining the causes of stillbirth. Bull World Health Organ. 2011;89(1):31-40.

20. Victora CG, Huttly SR, Fuchs SC, Olinto MT. The role of conceptual frameworks in epidemiological analysis: a hierarchical approach. Int J Epidemiol. 1997;26(1): 224-7.

21. McClure EM, Goldenberg RL, Bann CM. Maternal mortality, stillbirth and measures of obstetric care in developing and developed countries. Int J Gynaecol Obstet. 2007;96(2):139-46.

22. Negandhi PH, Neogi SB, Chopra S, Phogat A, Sahota R, Gupta R, Gupta R, Zodpey S. Improving reporting of infant deaths, maternal deaths and stillbirths in Haryana, India. Bull World Health Organ. 2016;94(5):370-5.

23. Frøen JF, Gordijn SJ, Abdel-Aleem H, Bergsjø P, Betran A, Duke CW, Fauveau V, Flenady V, Hinderaker SG, Hofmeyr GJ. Making stillbirths count, making numbers talk-issues in data collection for stillbirths. BMC pregnancy and childbirth. 2009;9(1):1.

24. Haws RA, Yakoob MY, Soomro T, Menezes EV Darmstadt GL, Bhutta ZA Reducing stillbirths: screening and monitoring during pregnancy and labour. BMC pregnancy and childbirth. 2009;9(1):1.

25. Allen VM, Joseph K, Murphy KE, Magee LA, Ohlsson A. The effect of hypertensive disorders in pregnancy on small for gestational age and stillbirth: a population based study. BMC pregnancy and childbirth. 2004;4(1):1.

26. Ananth CV, Savitz DA, Bowes WA. Hypertensive disorders of pregnancy and stillbirth in North Carolina, 1988 to 1991. Acta Obstet Gynecol Scand. 1995;74(10):788-93.

27. Marufu TC, Ahankari A, Coleman T, Lewis S. Maternal smoking and the risk of still birth: systematic review and meta-analysis. BMC Public Health. 2015;15(1):1.

28. Silverman JG, Gupta J, Decker MR, Kapur N, Raj A. Intimate partner violence and unwanted pregnancy, miscarriage, induced abortion, and stillbirth among a national sample of Bangladeshi women. BJOG Int J Obstet Gynaecol. 2007;114(10):1246-52.

29. de Bernis L, Kinney MV, Stones W, Ten Hoope-Bender P, Vivio D, Leisher SH, Bhutta ZA, Gulmezoglu M, Mathai M, Belizan JM, et al. Stillbirths: ending preventable deaths by 2030. Lancet. 2016:387(10019):703-16

30. Himabindu BL, Arora R, Prashanth NS. Whose problem is it anyway? Crimes against women in India. Glob Health Action. 2014;7:23718.

31. Goldenberg RL, McClure EM, Bann CM. The relationship of intrapartum and antepartum stillbirth rates to measures of obstetric care in developed and developing countries. Acta Obstet Gynecol Scand. 2007;86(11):1303-9.
32. Darmstadt GL, Yakoob MY, Haws RA, Menezes EV, Soomro T, Bhutta ZA. Reducing stillbirths: interventions during labour. BMC Pregnancy and Childbirth. 2009;9(1):1.

33. Bhutta ZA, Das JK, Bahl R, Lawn JE, Salam RA, Paul VK, Sankar MJ, Blencowe H, Rizvi A, Chou VB. Can available interventions end preventable deaths in mothers, newborn babies, and stillbirths, and at what cost? Lancet. 2014;384(9940):347-70.

34. Feresu SA, Harlow SD, Welch K, Gillespie BW. Incidence of and sociodemographic risk factors for stillbirth, preterm birth and low birthweight among Zimbabwean women. Paediatr Perinat Epidemiol. 2004;18(2):154-63.

35. Flenady V, Wojcieszek AM, Middleton P, Ellwood D, Erwich JJ, Coory M, Khong TY, Silver RM, Smith GC, Boyle FM, et al. Stillbirths: recall to action in high-income countries. Lancet. 2016;387(10019):691-702.

36. Pattinson R, Kerber K, Buchmann E, Friberg IK, Belizan M, Lansky S, Weissman E, Mathai M, Rudan I, Walker N, et al. Stillbirths: how can health systems deliver for mothers and babies? Lancet. 2011;377(9777):1610-23.

37. Dujardin B, Boutsen M, De Schampheleire I, Kulker R, Manshande JP, Bailey J, Wollast E, Buekens P. Oxytocics in developing countries. Int J Gynaeco Obstet. 1995;50(3):243-51.

38. WHO recommendations for augmentation of labour [www.who.int/iris/ bitstream/10665/112825/1/9789241507363_eng.pdf].

39. Froen JF, Friberg IK, Lawn JE, Bhutta ZA, Pattinson RC, Allanson ER, Flenady V, McClure EM, Franco L, Goldenberg RL, et al. Stillbirths: progress and unfinished business. Lancet. 2016;387(10018):574-86.

40. Nausheen S, Soofi SB, Sadiq K, Habib A, Turab A, Memon Z, Khan MI, Suhag Z, Bhatti Z, Ahmed I, et al. Validation of verbal autopsy tool for ascertaining the causes of stillbirth. PLoS One. 2013;8(10):e76933.

\section{Submit your next manuscript to BioMed Central and we will help you at every step:}

- We accept pre-submission inquiries

- Our selector tool helps you to find the most relevant journal

- We provide round the clock customer support

- Convenient online submission

- Thorough peer review

- Inclusion in PubMed and all major indexing services

- Maximum visibility for your research

Submit your manuscript at www.biomedcentral.com/submit
) Biomed Central 